\title{
Changes Associated with Laboratory Rearing in Antennal Sensilla Patterns of Triatoma infestans, Rhodnius prolixus, and Rhodnius pallescens (Hemiptera, Reduviidae, Triatominae)
}

\author{
SS Catalá/ ${ }^{+}$, DM Maida, H Caro-Riaño*, N Jaramillo*, J Moreno* \\ Centro Regional de Investigación Científica y Transferencia Tecnológica de La Rioja, Anillaco, 5301, Argentina \\ *Grupo de Morfometría Biológica, Instituto de Biología, Universidad de Antioquia, Medellin, Colombia
}

We examined changes in the array of antennal sensilla of three species of Triatominae (Triatoma infestans, Rhodnius prolixus, and R. pallescens) following their establishment for different periods in laboratory culture. In each case, the laboratory colonies were compared with conspecific samples taken directly from the field, by quantitative analysis of the sensilla arrays on the three distal segments of the antenna in terms of the densities of three types of chemoreceptors (basiconics and thick and thin walled trichoids) and one type of mechanoreceptor (bristles). Sensilla densities were compared by ANOVA or non-parametric tests, and by multivariate discriminant analysis. Strains of the same species reared in different laboratories showed significant differences in their sensilla arrays, especially when compared to field-collected material from the same geographic origin. A Bolivian strain of $\mathrm{T}$. infestans reared in the laboratory for 15 years and fed at monthly intervals, showed greatest differences from its conspecific wild forms, especially in terms of reductions in the number of chemoreceptors. By contrast, an Argentine strain of $\mathrm{T}$. infestans reared for 25 years in the laboratory and fed weekly, showed a relative increase in the density of mechanoreceptors. A Colombian strain of R. prolixus reared for 20 years and fed weekly or fortnightly, showed only modest differences in the sensilla array when compared to its wild populations from the same area. However, a Colombian strain of R. pallescens reared for 12 years and fed fortnightly, did show highly significant reductions in one form of chemoreceptor compared to its conspecific wild populations.

For all populations, multivariate analysis clearly discriminated between laboratory and field collected specimens, suggesting that artificial rearing can lead to modifications in the sensory array. This not only supports the idea of morphological plasticity in these species, but also suggests caution in the use of long-established laboratory material for experimental studies designed to extrapolate the natural behaviour and physiology of these species.

Key words: Triatoma infestans - Rhodnius prolixus - Rhodnius pallescens - antennal-sensilla - Chagas disease - laboratory-rearing

The Triatominae (Hemiptera, Reduviidae) represent a well-characterized subfamily defined on the basis of their blood-sucking habit and associated morphological characteristics. Over 130 species are now recognized, customarily grouped into 19 genera and 5 tribes, many of which have epidemiological importance as domestic vectors of Trypanosoma cruzi, causative agent of Chagas disease in Latin America.

In various species of Triatominae, a series of morphological and genetic changes has been observed associated with their adaptation from silvatic to domestic habitats. These changes generally involve morphological and genetic simplification, together with reductions in average size and in degree of sexual dimorphism, and a relaxation of bilateral symmetry (Schofield 1994, Schofield et

Financial support: ECLAT network, Colciencias, Fundación para la Promoción de la Investigación y Desarrollo Tecnológico Banco de la Republica-Colombia, CODI-U. de A, and Gobierno de la Generalitat Valenciana, España

${ }^{+}$Corresponding author. Fax: +54-3827.494231. E-mail: scatala@crilar-conicet.com.ar

Received 18 August 2003

Accepted 3 December 2003 al. 1999, Dujardin et al. 1997 a,b, 1998, 1999 a,b, 2000). Similar changes can be observed in some laboratory populations, especially in terms of reductions in average size and volume of blood ingested while feeding (Szumlewicz 1976), and in some cases reduction in wing size, thoracic musculature, and flight capacity (Soares 1997).

As part of a wider study on the adaptive trends in Triatominae, we have been examining changes in the antennal sensilla arrays in a number of species. According to the number, type, and distribution of antennal sensilla, it has been possible to distinguish genera, species, and sex, and the sensilla arrays are now being used to compare adaptations of different populations in terms of their habitat and geographical distribution (Catalá 1996, 1997, 1998, Gracco \& Catalá 2000, Dujardin et al. 2000, Noireau et al. 2000, Catalá \& Dujardin 2001, Catalá \& Torres 2001, Carbajal de la Fuente \& Catalá 2002).

In the present work, we wished to determine possible changes in sensilla arrays associated with adaptation to laboratory culture. We compared various strains of three species, two of which recognized as primarily domestic species (Triatoma infestans and Rhodnius prolixus) are the main vectors of Chagas disease in South América and a third ( $R$. pallescens) which is primarily sylvatic but known to form small domestic and peridomestic colonies in parts of Colombia. 


\section{MATERIALS AND METHODS}

The insects - Details of their origin are given below, with full maintenance conditions for the laboratory strains summarized in Table I.

\section{T. infestans}

Domestic strains - We examined 5 males and 5 females from each of two samples of $T$. infestans collected directly from houses in Cochabamba, Bolivia (strain BD) and from La Rioja, Argentina (strain AD).

Laboratory strains - We examined 8 males and $8 \mathrm{fe}-$ males of T. infestans originating from a colony maintained for 18 years ( 9 generations) in an Argentine laboratory (Lab. A) (strain BL). This colony had originally been founded in 1984 from parental bugs collected in houses near Santa Cruz, Bolivia. In Lab. A, the maintenance conditions were very variable. When there had been no demand for these insects, they had been maintained at ambient temperature $\left(12-24^{\circ} \mathrm{C}\right)$ and offered a bloodmeal at monthly intervals. However, on occasions when it was required to increase the size of the colony, the temperature was increased to $27^{\circ} \mathrm{C}$ and bloodmeals were offered at intervals of 7-10 days.

We also examined 5 males and 5 females originating from another Argentine laboratory (Lab. B) (strain AL). This strain had been founded from insects collected from houses in central Argentina in 1975, and maintained under controlled conditions at $28-30^{\circ} \mathrm{C}$ with a weekly bloodmeal feeding regime.

\section{R. prolixus}

Domestic strain - We examined 5 males and 5 females of $R$. prolixus collected directly from houses in the departments of Tolima and Cundinamarca, Colombia (strain RPD).

Laboratory strain - We examined 5 males and 5 females of $R$. prolixus originating from a 20 year-old laboratory colony at the University of Santander, Colombia, but maintained in Lab. B in Argentina since March 1998 (strain RPL) under conditions identical to those described for $T$. infestans strain AL.

\section{R. pallescens}

Silvatic strain - We examined 4 males collected directly from palm tree crowns (Attalea butyracea) in the Department of Antioquia, Colombia (strain P).

Laboratory strain - We examined 7 males and 3 females of $R$. pallescens originating from the Department of Antioquia, Colombia, and maintained in laboratory cul- ture at the University of Antioquia since 1989 (approximately 20 generations) (strain P20). We also examined 5 males from the first generation of laboratory offspring from strain $\mathrm{P}(\mathrm{P} 1)$.

Analysis of sensilla patterns - For the analysis of antennal sensilla patterns, one antenna was cut from each individual at the level of the scape (segment 1). The antenna was cleared in $4 \%$ potassium hydroxide, neutralized with $5 \%$ acetic acid, and slide-mounted in glycerine. By optical microscopy at 400x, the number of sensilla of different types was counted over the whole ventral surface of the three distal segments of the antenna (pedicel, P; flagellar segment 1, F1; and flagellar segment 2, F2). For this study, we considered three types of chemoreceptors (thin-walled trichoids, TH; thick-walled trichoids, TK; basiconics, BA) and one type of mechanoreceptor (bristles, BR) (nomenclature following Catalá \& Schofield 1994).

Means and variances of the number of each sensilla type on each segment (Table II) were checked for homogeneity of variance (Levene's test) followed by ANOVA to compare means between groups. Those showing significant heteroscedasticity were compared using non-parametric tests after log-transformation (Mann-Whitney, Kolmogorov-Smirnov, Wald-Wolfowitz). Differences with a value of p 0.015 were considered significant, while differences with a value of $p$ between 0.016 and 0.05 were considered as tendencies. A multivariate discriminant analysis was made using log-transformed data and the software STATISTICA. The significance of Mahalanobis distances was also tested by non-parametric procedures (500 permutations) using PADWIN (JPDujardin, software available at the http://life.bio.sunysb.edu/morph).

\section{RESULTS}

T. infestans - Females of the laboratory strain of $T$. infestans from Bolivia (BL) showed a significant reduction in the numbers of thick-walled trichoids on the first flagellar segment (F1TK) compared to recently collected females from Bolivia ( $\mathrm{p}$ 0.002), together with a tendency to reduced numbers of basiconica on the second flagellar segment (F2BA) (p 0.029) and reduced thin-walled trichoids on the pedicel (PTH) (p 0.045). Males from the Bolivian laboratory strain also showed significant reductions in the F2BA ( $\mathrm{p} 0.011$ ) compared to recently collected males, but showed significant increases in the F1TH (p 0.007 ) and F2BR (p 0.009). Laboratory reared males from

TABLE I

Laboratory rearing conditions for the laboratory strains of Triatoma infestans, Rhodnius prolixus, and R. pallescens

\begin{tabular}{|c|c|c|c|c|c|c|c|c|}
\hline Species & Strain & $\begin{array}{c}\text { Temperature } \\
{ }^{\circ} \mathrm{C}\end{array}$ & $\begin{array}{c}\text { Humidity } \\
\%\end{array}$ & $\begin{array}{c}\text { Fotofase } \\
\text { Hs }\end{array}$ & $\begin{array}{l}\text { Feeding } \\
\text { frequency }\end{array}$ & $\begin{array}{l}\text { Years } \\
\text { in lab }\end{array}$ & $\begin{array}{c}\text { Flask } \\
\text { size } \mathrm{cm}^{3} a\end{array}$ & $\begin{array}{r}\text { Individuals } \\
\text { per flask }\end{array}$ \\
\hline T. infestans & $\mathrm{BL}$ & $12-27$ & $50-70$ & 8 & Monthly to weekly & 18 & 101 & 30 \\
\hline T. infestans & $\overline{\mathrm{AL}}$ & $28-30$ & $50-60$ & 12 & Weekly & +25 & 39 & $300-400$ \\
\hline R. prolixus & RPL & $25-27$ & $75-80$ & 12 & Fortnightly & +20 & 20 & 150 \\
\hline R. pallescens & $\mathrm{P} 20$ & $22-28$ & $75-85$ & 12 & Fortnightly & +13 & 53 & 80 \\
\hline R. pallescens & $\mathrm{P} 1$ & $22-28$ & $75-85$ & 12 & Fortnightly & 1 & 53 & 80 \\
\hline
\end{tabular}

$a$ : relative flask size calculated as: volume of flask/number of individuals per flask; BL: T. infestans Bolivia laboratory; AL: T. infestans Argentina laboratory; RPL: R. prolixus laboratory; P20: R. pallescens laboratory 20 generations; P1: $R$. pallescens laboratory, first generation 
TABLE II

Mean (standard deviation) of the number of sensilla on each antennal segment of the populations examined

\begin{tabular}{|c|c|c|c|c|c|c|c|c|c|c|c|c|c|}
\hline \multirow[b]{2}{*}{ Species } & \multicolumn{3}{|c|}{ Ped } & \multicolumn{3}{|c|}{ F 1} & \multicolumn{5}{|c|}{ F 2} & \multicolumn{2}{|r|}{ Sensilla } \\
\hline & $\mathrm{x}$ & & TH & BA & $\mathrm{BR}$ & TH & TK & BA & $\mathrm{BR}$ & TH & TK & BA & \\
\hline $\begin{array}{l}m a \\
\text { ans (BD) }\end{array}$ & $\mathrm{B}$ & $1,2)$ & $\begin{array}{c}65,2 \\
(11,3)\end{array}$ & $\begin{array}{c}1,8 \\
(1,3)\end{array}$ & $\begin{array}{c}14 \\
(3,5)\end{array}$ & $\begin{array}{c}53,4 \\
(15,6)\end{array}$ & & $\begin{array}{c}38,6 \\
(18,8)\end{array}$ & $\begin{array}{c}7,2 \\
(1,8)\end{array}$ & $\begin{array}{l}2,2 \\
0,1)\end{array}$ & $\begin{array}{l}213 \\
(8,8)\end{array}$ & & $\begin{array}{l}848,4 \\
(89,1)\end{array}$ \\
\hline & M & $\begin{array}{l}140,8 \\
(12,2)\end{array}$ & $\begin{array}{l}122,4 \\
(36,2)\end{array}$ & $\begin{array}{c}0,4 \\
(0,5)\end{array}$ & $\begin{array}{l}13,8 \\
(3,6)\end{array}$ & $\begin{array}{c}69,6 \\
(11,8)\end{array}$ & $\begin{array}{c}252 \\
(57,1)\end{array}$ & $\begin{array}{c}37 \\
(19,2)\end{array}$ & $\begin{array}{c}7,2 \\
(1,4)\end{array}$ & & $\begin{array}{c}218 \\
(12,3)\end{array}$ & $\begin{array}{c}46,8 \\
(17,9)\end{array}$ & $\begin{array}{c}937,8 \\
(121,3)\end{array}$ \\
\hline iatoma & $\mathrm{M}$ & $\begin{array}{c}161 \\
(11,6) \\
148,7 \\
(7,3)\end{array}$ & $\begin{array}{c}48,3 \\
(12,4) \\
112,8 \\
(22,8)\end{array}$ & $\begin{array}{c}0,12 \\
(0,3) \\
0 \\
(0)\end{array}$ & $\begin{array}{c}20 \\
(5,9) \\
16 \\
(3,9)\end{array}$ & $\begin{array}{c}52 \\
(27,2) \\
97,7 \\
(14,8)\end{array}$ & $\begin{array}{c}144,5 \\
(7,7) \\
201 \\
(56,6)\end{array}$ & $\begin{array}{l}14,6 \\
(5,6) \\
20,8 \\
(7,6)\end{array}$ & $\begin{array}{c}10,1 \\
(7,7) \\
9,7 \\
(1,2)\end{array}$ & $\begin{array}{l}(5 \\
35 \\
(5\end{array}$ & & & $\begin{array}{c}719,1 \\
(85,9) \\
899 \\
(105,1)\end{array}$ \\
\hline Triatoma & M & $\begin{array}{c}143,6 \\
(11,2) \\
145,4 \\
(9,3)\end{array}$ & $\begin{array}{l}140,2 \\
(19,8) \\
242,4 \\
(32,7)\end{array}$ & $\begin{array}{c}1,4 \\
(0,8) \\
0,4 \\
(0,4)\end{array}$ & $\begin{array}{c}15 \\
(1,6) \\
11 \\
(0,8)\end{array}$ & $\begin{array}{c}65 \\
(0,9) \\
97,8 \\
(11,1)\end{array}$ & $\begin{array}{l}450,2 \\
(53,4) \\
469,6 \\
(56,5)\end{array}$ & $\begin{array}{c}30,4 \\
(16,8) \\
41,2 \\
(10,0)\end{array}$ & $\begin{array}{c}7,4 \\
(0,8) \\
5,6 \\
(1,3)\end{array}$ & $\begin{array}{c}30,6 \\
(7,7) \\
38 \\
(4,6)\end{array}$ & & & $\begin{array}{c}1184 \\
(60,1) \\
1367,4 \\
(64,4)\end{array}$ \\
\hline Triatoma & $\mathrm{M}$ & $\begin{array}{c}162,6 \\
(10,4) \\
152,4 \\
(12,3)\end{array}$ & $\begin{array}{l}150,6 \\
(17,0) \\
222,8 \\
(36,5)\end{array}$ & $\begin{array}{c}1,2 \\
(1,4) \\
1 \\
(1,1)\end{array}$ & $\begin{array}{c}16,2 \\
(4,71) \\
13,4 \\
(1,0)\end{array}$ & $\begin{array}{c}83,8 \\
(12,5) \\
96,4 \\
(13,0)\end{array}$ & $\begin{array}{l}495 \\
(70,\end{array}$ & $\begin{array}{r}5 \\
(13 \\
48 \\
(17\end{array}$ & $\begin{array}{c}10,2 \\
(1,9) \\
8,8 \\
(1,9)\end{array}$ & $\begin{array}{l}36 \\
(4 \\
37 \\
(5\end{array}$ & $\begin{array}{r}26 \\
(27 \\
26 \\
(27\end{array}$ & $\begin{array}{r}42 \\
(12 \\
36 \\
(1\end{array}$ & $\begin{array}{l}1298,6 \\
(113,6) \\
1380,4 \\
(133,2)\end{array}$ \\
\hline $\begin{array}{l}\text { ius } \\
\iota s \text { (RPD) }\end{array}$ & M & $\begin{array}{c}149,4 \\
(35,8) \\
120,3 \\
(23,5)\end{array}$ & $\begin{array}{c}0 \\
(0) \\
0 \\
(0)\end{array}$ & $\begin{array}{c}0 \\
(0) \\
0 \\
(0)\end{array}$ & $\begin{array}{l}41,8 \\
(5,6) \\
33,8 \\
(9,6)\end{array}$ & $\begin{array}{c}116,3 \\
(40,7) \\
55,8 \\
(25,5)\end{array}$ & $\begin{array}{c}159,7 \\
(30,4) \\
138 \\
(40,9)\end{array}$ & $\begin{array}{c}25 \\
(10,8) \\
19,1 \\
(8,8)\end{array}$ & $\begin{array}{c}15,2 \\
(5,6) \\
13,1 \\
(2,7)\end{array}$ & $\begin{array}{c}70,8 \\
(36,4) \\
71,6 \\
(22,7)\end{array}$ & $\begin{array}{c}169,1 \\
(22,6) \\
164,5 \\
(21,4)\end{array}$ & $\begin{array}{c}30,8 \\
(10,0) \\
32,6 \\
(6,5)\end{array}$ & $\begin{array}{c}778,4 \\
(157,3) \\
682,6 \\
(59,8)\end{array}$ \\
\hline $\begin{array}{l}\text { ius } \\
\text { isPL) }\end{array}$ & $\mathrm{M}$ & $\begin{array}{c}101 \\
(6,3) \\
102,8 \\
(6,1)\end{array}$ & $\begin{array}{c}0 \\
(0) \\
0 \\
(0)\end{array}$ & $\begin{array}{c}0 \\
(0) \\
0 \\
(0)\end{array}$ & $\begin{array}{l}27,2 \\
(5,6) \\
26,8 \\
(5,2)\end{array}$ & $\begin{array}{c}83 \\
(11,2) \\
70 \\
(17,9)\end{array}$ & $\begin{array}{l}147,2 \\
(24,3) \\
177,6 \\
(23,1)\end{array}$ & $\begin{array}{l}21,2 \\
(8,6) \\
29,2 \\
(2,7)\end{array}$ & $\begin{array}{c}12,2 \\
(1,9) \\
11,2 \\
(3,7)\end{array}$ & $\begin{array}{c}32,2 \\
(11,6) \\
44,6 \\
(9,5)\end{array}$ & $\begin{array}{c}194,6 \\
(36,6) \\
185 \\
(5,4)\end{array}$ & $\begin{array}{c}33,8 \\
(5,4) \\
35,4 \\
(4,9)\end{array}$ & $\begin{array}{c}652,4 \\
(74,9) \\
682,6 \\
(59,8)\end{array}$ \\
\hline $\begin{array}{l}\text { Rhodnius } \\
\text { pallescens }(\mathrm{P})\end{array}$ & 1 & $\begin{array}{c}82,2 \\
(13,7)\end{array}$ & $\begin{array}{c}0 \\
(0)\end{array}$ & $\begin{array}{c}0 \\
(0)\end{array}$ & $\begin{array}{l}19,8 \\
(1,3)\end{array}$ & $\begin{array}{l}74,6 \\
(14,7)\end{array}$ & $(7,4)$ & $(4,5)$ & $\begin{array}{l}8,2 \\
(3,0)\end{array}$ & $\begin{array}{l}46,6 \\
(20,0)\end{array}$ & & & $\begin{array}{l}450,6 \\
(73,3)\end{array}$ \\
\hline $\begin{array}{l}\text { Rhodnius } \\
\text { pallescens }(\mathrm{P} 1)\end{array}$ & M & $\begin{array}{l}80,2 \\
(2,9)\end{array}$ & $\begin{array}{c}0 \\
(0)\end{array}$ & $\begin{array}{c}0 \\
(0)\end{array}$ & $\begin{array}{l}21,5 \\
(3,4)\end{array}$ & $\begin{array}{l}82,5 \\
(6,4)\end{array}$ & $\begin{array}{r}109,7 \\
(9,1)\end{array}$ & $\begin{array}{l}23,0 \\
(2,94)\end{array}$ & $\begin{array}{l}8,2 \\
(2,8)\end{array}$ & $\begin{array}{l}45,5 \\
(5,3)\end{array}$ & $\begin{array}{c}92,0 \\
(23,1)\end{array}$ & $\begin{array}{l}25,2 \\
(11,5)\end{array}$ & $\begin{array}{c}488 \\
(67,7)\end{array}$ \\
\hline $\begin{array}{l}\text { Rhodnius } \\
\text { pallescens (P20) }\end{array}$ & M & $\begin{array}{c}79,0 \\
(7,5) \\
72,5 \\
(5,3)\end{array}$ & $\begin{array}{c}0 \\
(0) \\
0 \\
(0)\end{array}$ & $\begin{array}{c}0 \\
(0) \\
0 \\
(0)\end{array}$ & $\begin{array}{l}20,6 \\
(4,1) \\
20,5 \\
(1,2)\end{array}$ & $\begin{array}{c}67,3 \\
(15,1) \\
58,5 \\
(7,8)\end{array}$ & $\begin{array}{c}93,6 \\
(12,0) \\
94,1 \\
(19,6)\end{array}$ & $\begin{array}{l}20,3 \\
(6,4) \\
19,2 \\
(3,9)\end{array}$ & $\begin{array}{c}10,3 \\
(1,1) \\
9,2 \\
(2,1)\end{array}$ & $\begin{array}{l}40,0 \\
(1,0) \\
40,8 \\
(7,4)\end{array}$ & $\begin{array}{c}101,0 \\
(12,1) \\
85,8 \\
(15,6)\end{array}$ & $\begin{array}{l}18,0 \\
(5,0) \\
20,1 \\
(4,7)\end{array}$ & $\begin{array}{l}450,3 \\
(64,6) \\
421,3 \\
(67,9)\end{array}$ \\
\hline
\end{tabular}

Ped: pedicel; F 1: first flagellar segment; F 2: second flagellar segment. BR: bristles; TH: thin walled trichoids; TK: thick walled trichoids; BA: basiconics. T. infestans: BD: Bolivian domestic population; BL: Bolivian laboratory strain; AD: Argentine domestic population; AL: Argentine laboratory population. R. prolixus: RPD: Colombian domestic population; RPL: Colombian laboratory population. $R$. pallescens: P: Colombian sylvatic population; P1: first generation laboratory offspring from population P; P20:

Colombian laboratory population

Argentina (AL) also showed increased numbers of F1BR (p 0.008) and a tendency to increase PBR (p 0.038) and F2BR (p 0.027), compared to the domestic Argentine specimens (AD).

Discriminant analysis to compare the domestic and laboratory strains was highly significant (F 11.74, p 0.0000) with the four most significant variables being F1TK, F1TH, F1BR, F2BA. Ninety four percent of Bolivian laboratory specimens (BL) were correctly reclassified, together with $90 \%$ of domestic Bolivian (BD), $70 \%$ of domestic Argentine specimens (AD), and 50\% of the laboratory Argentine specimens (AL). The first discriminant function (FD1) separated the two Argentine populations from those from Bolivia (geographical separation), while the second (FD2) separated the two Bolivian populations from each other (separation by habitat). Neither function separated the two Argentine populations (Fig. 1). Variables presenting highest coefficients within FD1 (geographical separation) were F1TH and F1TK, while those with highest coefficients within FD2 (separation by habitat) were F2BA and F1BR. Mahalanobis distances calculated as the distance between group centroids were significantly different between the two domestic groups, and between the Bolivian domestic and laboratory strains, but not between the domestic and laboratory Argentine strains.

$R$. prolixus sensilla of the two Colombian strains of $R$. prolixus showed no significant differences, although there was a trend for laboratory reared females to have a reduced number of F2BR (p 0.048) and an increase in F2BA (p 0.021). Laboratory reared males also showed a tendency for reduced numbers of F2TH (p 0.041) and increased numbers of F1BA ( $\mathrm{p} 0.044)$. 


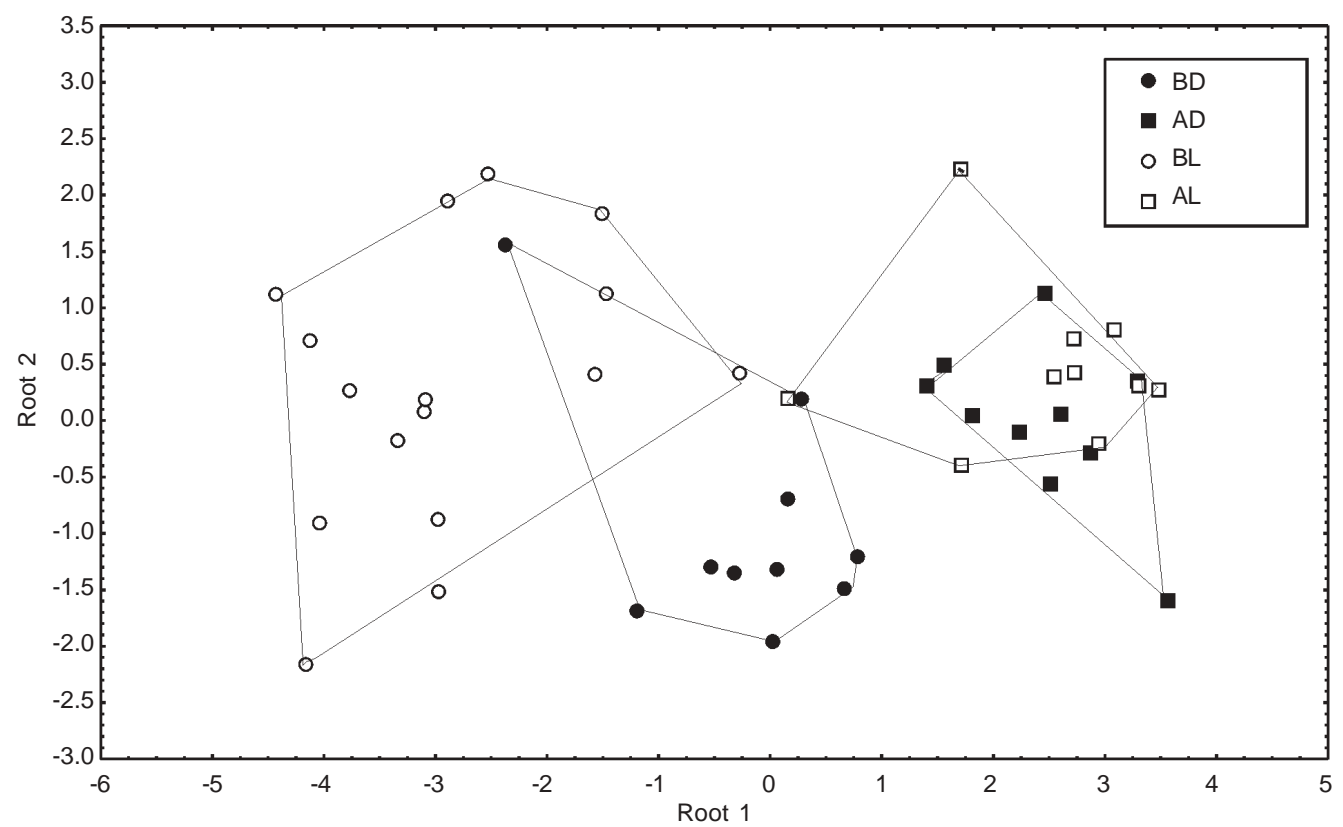

Fig. 1: discriminant analysis of domestic (BD, Bolivia and AD, Argentina) and laboratory strains (BL, Bolivia and AL, Argentina) of Triatoma infestans from Bolivia and Argentina

The discriminant analysis clearly separated the laboratory and domestic strains (F 18.69, p 0.0000), and all individuals were correctly reclassified to group (Fig. 2). The variables presenting highest discriminant coefficients were F2TH and F2BA.

R. pallescens By ANOVA and Mann-Whitney U-test, there were no significant differences between sexes within each group, so that sexes were combined for the subsequent analyses. Comparison of the three strains showed a tendency for reduction in numbers of PBR, F1TH, F2TH, and F2BA in the P20 strain that had been in colony for 20 generations. However, these differences were not statistically significant ( $\mathrm{p} 0.015$ ) except in the case of the thinwalled trichoids on flagellar segment 1 (F1TH) (p 0.001).

Discriminant analysis using F1TH, F2BR, and F2BA was significant ( $\mathrm{F} \quad 6.93$, p 0.001) with F2BR, and F2BA showing the highest coefficients ( $\mathrm{p} 0.001$ ). Mahalanobis

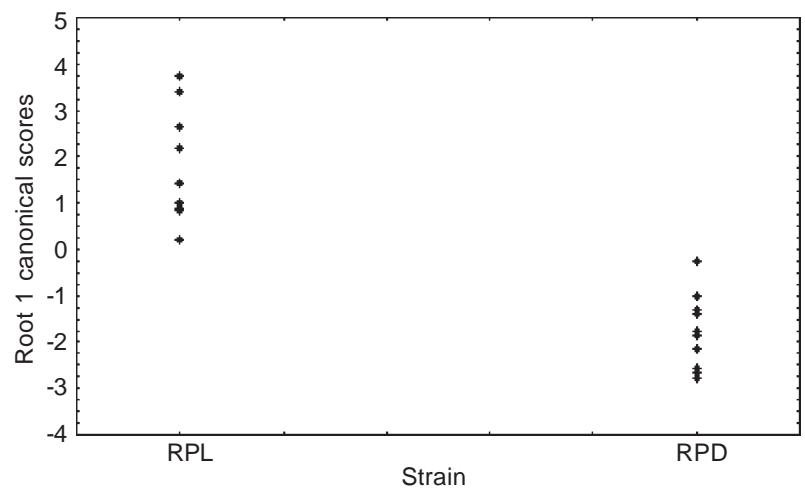

Fig. 2: canonical scores (from discriminant analysis root 1) for Rhodnius prolixus domestic strain (RPD) and laboratory strain (RPL) distances were significant ( $\mathrm{p} 0.001$ ) between P20 and the other two groups (P 16.2 and P1 = 24.8) (Fig. 3).

\section{DISCUSSION}

Considering the laboratory as a new habitat for Triatominae, various authors have reported changes in the phenotype associated with different rearing conditions. These have included reduction in average body size, reduced bilateral symmetry and sexual dimorphism, and changes in size and shape of the head and pronotum (eg. Gómez-Nuñez \& Fernández 1963, Szumlewicz 1976, Dujardin et al. 1998, Galíndez Girón et al. 1999). According to Dujardin (1998), the reduction in body size may reflect the higher population density of bugs maintained in the laboratory, and corresponding reductions in average bloodmeal size. In natural populations, adults of $T$. infestans can feed at intervals of 2-3 days (Catalá 1991, 1994, Catalá et al. 1992, López et al. 1999), whereas in laboratory culture the interval between available bloodmeals is invariably greater. In the present work, bloodmeals were offered to the various laboratory cultures of bugs at intervals of 1 to 4 weeks, and we observed reductions in body size of the laboratory strains of $T$. infestans (AL) and $R$. pallescens ( $\mathrm{P} 20)$ compared to their recently collected wild forms, as well as a reduction in the average wing length of the BL laboratory strain of $T$. infestans. These observations lend support to the idea that the availability of nutritional resources can affect the phenotype of the bugs, and also suggests that there may be corresponding changes in the physiology and behaviour of the insects.

The antennal sensilla of Triatominae are known to show a degree of morphological plasticity between populations that seems associated with adaptations to sensorial requirements of different habitats (Catalá 1997). It thus seemed logical to expect that by placing a popula- 


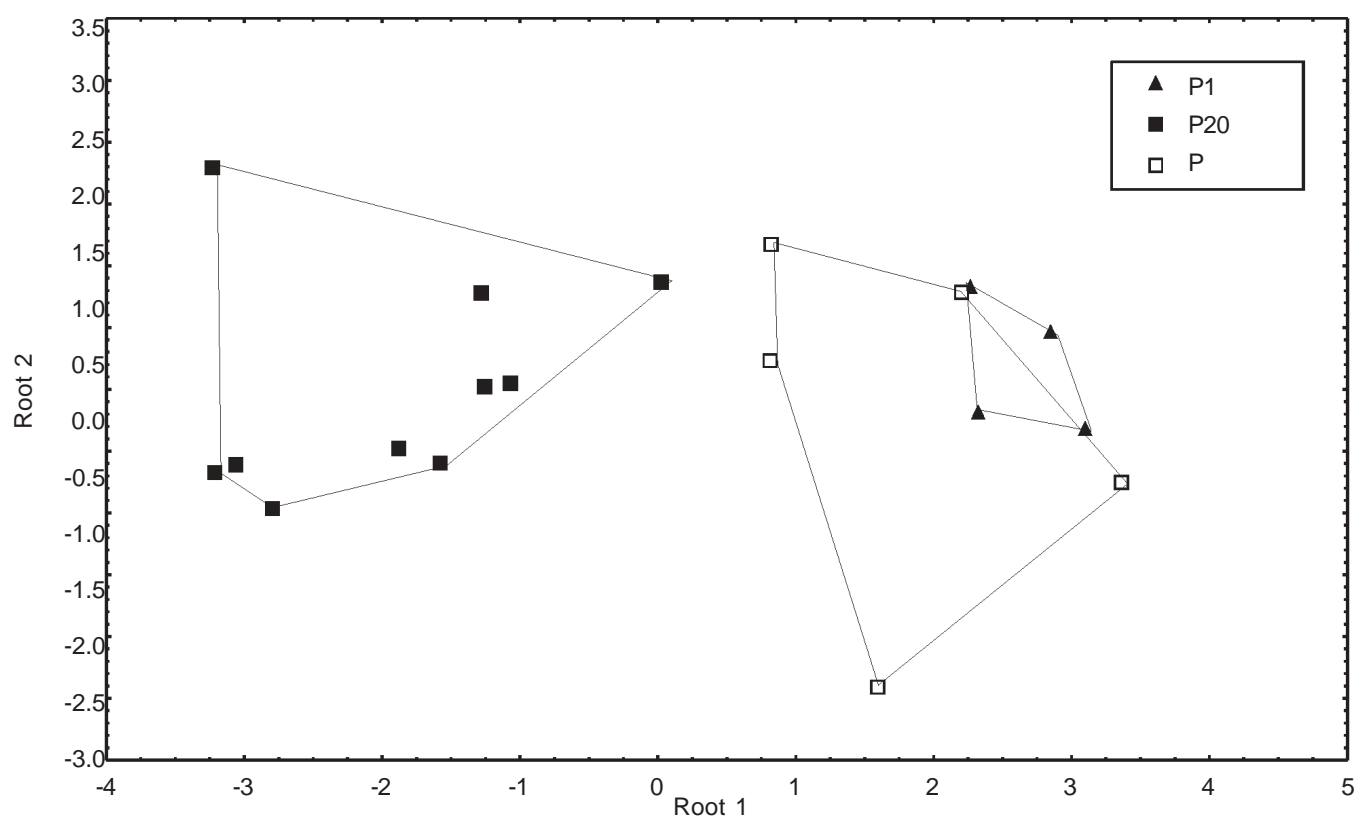

Fig. 3: discriminant analysis of the silvatic parental strain of Rhodnius pallescens $(\mathrm{P})$ and its first generation laboratory offspring (P1) compared to the strain maintained for 20 generations in the laboratory (P20)

tion in laboratory culture, which undoubtedly differs from its natural habitat, there may be some changes in the number of the sensory receptors. Our results confirm that laboratory rearing can lead to changes in the sensilla pattern, but that these changes may not be directly correlated to the time in laboratory culture. Greatest changes were seen in the BL strain of T. infestans that was reared under very variable conditions with longest intervals between bloodmeals. By contrast, the laboratory strains of $T$. infestans (AL), R. prolixus (RPL), and $R$. pallescens (P20) that were offered bloodmeals at weekly or fortnightly intervals showed less significant changes when compared to their wild populations, supporting the idea that bloodmeal availability may be a key factor influencing the array of antennal sensilla.

In the specific case of $T$. infestans, it may not be coincidental that the Mahalanobis distances between groups reflect the geographic distances between their origins, even when comparing samples from Bolivia and Argentina that were both collected directly from domestic habitats. It may be that the domestic habitats in the two regions differ in terms of factors that influence the sensilla arrays. Further evidence to support such an idea is given by the results of Catalá and Dujardin (2001) who found that the Mahalonobis distance between neighbouring silvatic and domestic samples of T. infestans from Bolivia (based on antennal sensilla variables) was comparable to the distance between domestic specimens from Bolivia and Argentina, suggesting that genetic drift was stronger between ecotopes than between distant geographical domestic populations. The differences observed here between domestic and laboratory strains may be in part due to the geografic origin of the strains. However, the distance between origins of the two samples from Bolivia was similar to the distance between origins of the two populations from Argentina and only the Bolivian labora- tory colony showed significant modifications of the antennal sensilla pattern.

We would emphasise however, that the observed changes in sensilla patterns tended to be in particular sensilla types, rather than a general characteristic of the array. Moreover, the changes tended to be more marked in males than in females, so that laboratory culture can appear to establish a new form of sexual dimorphism at the level of antennal sensilla pattern. This would appear to show high specificity of the changes, most marked in the thin-walled trichoids ( $\mathrm{TH})$ that seem primarily to act as generalised chemoreceptors (Bernard 1974, Taneja \& Guerin 1995, 1997, Steinbrecht 1999) and the basiconics (BA) that seem primarily involved in detection of presumed pheromones in conspecific faeces (Taneja \& Guerin 1995, 1997).

Overall, the results presented here seem to support the conclusions of other authors (eg. Gómez-Núñez \& Fernández 1963, Szumlewicz 1976, Galíndez-Girón et al. 1999) that laboratory rearing can lead to morphological changes in Triatominae. The more stable conditions of laboratory culture may impose fewer demands on sensilla complexity, although we cannot generalise about increases or decreases in sensilla density associated with laboratory rearing, since both trends occurred in the species studied here. Moreover, the Argentine strain of T. infestans $\mathrm{AL}$, reared in the laboratory for 25 years, showed changes only in the density of mechanoreceptors (BR) that are believed to sense tactile information regarding the insect's immediate surroundings, including vibrations, variations in air current, and contact stimuli (Wigglesworth \& Gillett 1934, McIver \& Siemicki 1984, Lazzari \& Nuñez 1989). The fact that both sexes of this strain showed an increase in numbers of these sensilla may be related to the higher density of the bugs in the laboratory culture (see Table I). It would appear from our results that significant changes 
in the sensilla arrays can occur after relatively few generations in laboratory culture, but that the precise nature of these changes cannot yet be predicted in relation to specific rearing conditions. Nevertheless, since such changes may also reflect changes in underlying physiology and behaviour, we would caution against the use of laboratory-reared bugs for experiments that seek to extrapolate the natural behaviour of these insects.

\section{ACKNOWLEDGEMENTS}

To Dr CJ Schofield for the english version of the manuscript, Dr JP Dujardin for critical suggestions, the Argentine and Colombian laboratories who contributed with some of the laboratory reared specimens used in these studies.

\section{REFERENCES}

Bernard J 1974. Études Electrophysiologiques des Récepteurs Impliqués dans la Orientation vers l'Hôte et dans l'Acte Hematophage chez un Hémiptère Triatoma infestans, $\mathrm{PhD}$ Thesis, Université de Rennes, France.

Carbajal de la Fuente AL, Catalá S 2002. Relationship among the habitat and the antennal sensilla pattern of six species of Triatominae Hemiptera, Reduviidae. Mem Inst Oswaldo Cruz, 97: 1073-1077.

Catalá S 1991. The biting rate of Triatoma infestans in Argentina. Med Vet Entomol 5: 325-333.

Catalá S 1994. Bloodmeal size and nutritional status of Triatoma infestans under natural climatic conditions. Med Vet Entomol 8: 104-106.

Catalá S 1996. Los patrones de sensilla. In Proceedings of the International Workshop on Population Genetics and Control of Triatominae, Santo Domingo de los Colorados, Ecuador, INDRE, Mexico, p. 59-62.

Catalá S 1997. Antennal sensilla of Triatominae Hemiptera, Reduviidae. A comparative study of five genera. Int J Insect Morphol Embriol 26: 67-73.

Catalá S 1998. Patrones morfológicos de sensilla: reflejan la percepción del hábitat y los hospedadores? In Proceedings of the Second International Workshop on Population Genetics and Control of Triatominae, Tegucigalpa, Honduras, INDRE, Mexico, p. 49-52.

Catalá S, Dujardin JP 2001. Antennal sensilla patterns indicate geographic and ecotopic variability among Triatoma infestans Hemiptera: Reduviidae populations. J Med Entomol 38: 423-428.

Catalá S, Schofield CJ 1994. The antennal sensilla of Rhodnius. J Morphol 219: 193-203.

Catalá S, Torres M 2001. Similitude of the patterns of sensilla on the antennae of Triatoma melanosoma and Triatoma infestans. Ann Trop Med Parasitol 95: 287-295.

Catalá S, Gorla D, Basombrio M 1992. Vectorial transmission of Trypanosoma cruzi: an experimental field study with susceptible and immunized hosts. Am J Trop Med Hyg 47: 20-26.

Dujardin JP 1998. Population genetics and the natural history of domestication in Triatominae. Mem Inst Oswaldo Cruz. 93: 34-36.

Dujardin JP, Bermudez H, Casini C, Schofield CJ, Tibayrenc M 1997a. Metric differences between silvatic and domestic Triatoma infestans Heteroptera: Reduviidae in Bolivia. J Med Entomol 34: 544-551.

Dujardin JP, Bermudez H, Schofield CJ 1997b. The use of morphometrics in entomological surveillance of silvatic foci of Triatoma infestans in Bolivia. Acta Trop 66: 145-153.

Dujardin JP, Chavez T, Machane M, Solis S 1999b. Size, shape and genetics. Sexual dimorphism and environment. In
Proceedings of the Second International Workshop on Population Biology and Control of Triatominae, Tegucigalpa, Honduras, INDRE, México, p. 53-62.

Dujardin JP, Forgues G, Torrez M, Martinez E, Córdoba C, Gianella A 1998. Morphometrics of domestic Pastrongylus rufotuberculatus in Bolivia. Ann Trop Med Parasitol 92: 219-228.

Dujardin JP, Panzera F, Schofield CJ 1999a. Triatominae as a model of morphological plasticity under ecological pressure. Mem Inst Oswaldo Cruz 94 (Suppl.1): 223-228.

Dujardin JP, Schofield CJ, Panzera F 2000. Les Vecteurs de la Maladie de Chagas. Recherches Taxonomiques, Biologiques et Génétiques. Académie Royale des Sciences d'Outre-mer, Brussels, 162 pp.

Galíndez-Girón I, Torres E, Galvão C, Magalhães dos Santos C, Lizano E, Barazarte R, Marquez J 1999. Influência da manutençao em laboratório sobre o fenótipo de Rhodnius robustus, Larrouse 1927 Hemiptera, Reduviidae, Triatominae. Entomol Vect 6: 677-703.

Gómez-Nuñez, JC, Fernandez J 1963. La colonia de Rhodnius prolixus en el Instituto Venezolano de Investigaciones Científicas. Bol Inform Dir Malariol San Amb 3: 132-136.

Gracco M, Catalá S 2000. Inter-specific and developmental differences on the array of antennal chemoreceptors in four species of Triatominae Hemiptera: Reduviidae. Mem Inst Oswaldo Cruz 95: 67-74.

Lazzari CR, Nuñez JA 1989. The response to radiant heat and the estimation of the temperature of distant sources in Triatoma infestans. J Ins Physiol 35: 525-529.

López A, Crocco L, Morales G, Catalá S 1999. Feeding frequency and nutritional status of peridomestic populations of Triatoma infestans from Argentina. Acta Trop 73: 275281.

McIver SB, Siemicki R 1984. Fine estructure of antennal mechanosensilla of adult Rhodnius prolixus Stäl Hemiptera: Reduviidae. J Morphol 180: 19-28.

Noireau F, Bastrenta B, Catalá S, Dujardin JP, Panzera F, Torres M, Perez R, Jurberg J, Galvão C 2000. Sylvatic population of Triatoma infestans from the Bolivian Chaco: from field collection to characterization. Mem Inst Oswaldo Cruz 95 (Suppl.1) : 119-122.

Schofield CJ 1994. Triatominae: Biología y Control, Eurocommunica Publications, UK, 80 pp.

Schofield CJ, Diotaiuti L, Dujardin J 1999. The process of domestication in Triatominae. Mem Inst Oswaldo Cruz, 94 (Suppl.1): 375-378.

Soares RP 1997. Aspectos Biológicos, Bioquimicos e Morfologicos Relacionados a Atividades de Vôo das Principais Espécies Vetoras da Doença de Chagas no Brasil, MSc Thesis, Universidade Federal de Minas Gerais, Belo Horizonte, 94 pp.

Steinbrecht RA 1999. Olfactory Receptors. In: Atlas of Arthropod Receptors, Max-Planck-Institut für Verhaltensphysiologie, Seewiesen, Germany.

Szumlewicz AP 1976. Laboratory colonies of Triatominae, biology and population dynamics. In American Tripanosomiasis Research. PAHO Scientific Publication 318: 6382.

Taneja J, Guerin PM 1995. Oriented responses of the triatominae bugs Rhodnius prolixus and Triatoma infestans to vertebrate odours on a servosphere. J Comp Physiol 176: 455-464.

Taneja J, Guerin PM 1997. Ammonia attracts Triatoma: behavioural and neurophysiological data on nymphs. J Comp Physiol 181: 21-24.

Wigglesworth VB, Gillett JD 1934. The function of the antennae in Rhodnius prolixus Hemiptera and the mechanism of orientation to the host. J Exp Biol 11: 120-139. 